\title{
ARTURO THOMAS NOVOA
}

(1934-2007)

La muerte sorprendió a Arturo, a los 73 años, el domingo 12 de agosto de 2007, en la estación Baquedano del Metro en Santiago. Una muerte prematura para un geólogo en plena actividad profesional. Nos consternó profundamente a todos quienes disfrutamos de su amistad y, en especial, a quienes compartimos también el Instituto Nacional, la Universidad de Chile, beca en la Universidad de Munich, Alemania, y algunos años de trabajo profesional.

Su carácter fuertemente independiente marcó su desarrollo y vida profesional. Nunca se adaptó totalmente a los procedimientos un tanto burocráticos propios de un servicio geológico estatal ni a las rigideces habituales de la empresa privada. Esto gravitó en la distribución de su vida laboral, en la que se contabilizan sólo 12 años como empleado y 38 como exitoso consultor privado en las áreas de geología económica y de geología aplicada a la ingeniería, principalmente en la evaluación geotécnica primaria de proyectos hidroeléctricos.

Fiel a su lema de toda la vida: 'primero ver, luego pensar, y después hablar o escribir', siempre privilegió el trabajo efectivo en terreno, enfocado al objetivo que buscaba o que se le había encomendado, por sobre largas elucubraciones en la oficina. Sus análisis invariablemente se convertían en informes profesionales aun cuando correspondían a visitas breves. Es así como generó una cantidad asombrosa de documentación, de la cual una parte sustancial de su legado, fue donada por su familia a la Biblioteca Técnica de Sernageomin, donde también encontramos sus publicaciones de los años 60. Su archivo geológico es ahora una fuente de consulta para revisar información acerca de los lugares más apartados de Chile.

Sus informes sobre evaluación de prospectos mineros incluyen, por lo general, un marco geológico amplio. A falta de cartas topográficas de detalle, previo a la disponibilidad del GPS, Arturo hacía su propio levantamiento con brújula y telémetro.

En contraposición a su espíritu siempre abierto y comunicativo en diferentes aspectos de su vida y consecuente con sus ideas, al punto de haberle costado la visión de un ojo en una batalla campal en la Alameda a comienzos de los años 70, fue ex-

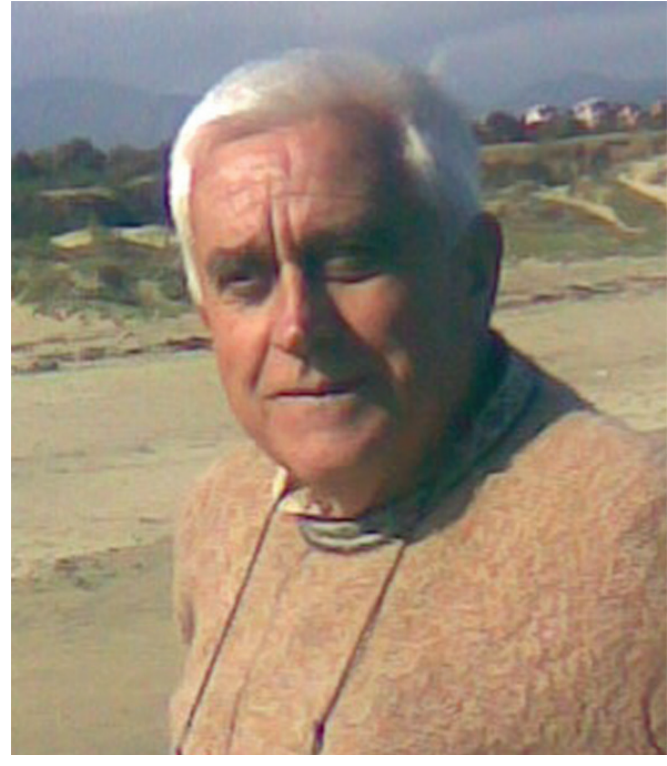

tremadamente reservado en relación a su actividad laboral. Por eso, solo un resumen somero de su currículum, que necesariamente debía actualizar para cada nuevo contratante, ha servido de base para este relato sobre su vida.

Un recorrido por su experiencia profesional permitirá conocer mejor y dar a conocer sus andanzas por el mundo como geólogo. Arturo fue tal vez el geólogo chileno que, en sus 50 años de actividad profesional, que se cumplieron justamente en este año 2007, se desempeñó en los lugares más diversos de América del Sur, Norteamérica, África y Asia. Su dominio de los idiomas maternos alemán y castellano, además del inglés y francés le facilitaron su accionar. Incluso adquirió durante su estadía de 2 años en Namibia conocimientos suficientes de dutch-africaans para desenvolverse con soltura en ese país.

Su primer empleo, en 1957, recién egresado de la universidad, fue en la Compañía Minera Aysén, para prospección en la zona del lago General Carrera. Luego optó por una beca por dos años en la Universidad de Munich, en Alemania, donde obtuvo el diplomado en Geología (equivalente a M.Sc.) con un levantamiento geológico de detalle en los Alpes. Ya con su diploma bajo el brazo, trabajó 
una temporada como asistente en el Departamento de Aguas Subterráneas de Israel, en el desierto de Negev. Pero no quería dejar Israel sin conocer el mítico Mar Muerto. Consiguió la difícil autorización, en ese tiempo, para visitarlo a condición de que portara un fusil ametralladora para autodefensa, para lo cual estaba preparado gracias a sus dos períodos de servicio militar realizado en Chile como estudiante, donde obtuvo su licencia como Sargento I con especialidad en armas pesadas.

De regreso en Chile, se incorporó al Instituto de Investigaciones Geológicas, con sede en Iquique y Antofagasta, hasta 1967, con mapeos regionales y de cuadrángulos, donde le cupo estudiar, entre otros, por primera vez, el ambiente geológico regional de los pórfidos cupríferos chilenos, desde Cerro Colorado hasta Los Pelambres. En 1964 asistió a un entrenamiento de 8 meses en fotointerpretación en el International Training Center en Delft, Holanda.

En 1967, desarrolló una consultoría en Irán para evaluar prospectos próximos a la ciudad de Ispahán y seleccionar puntos de exploración en la extensión a Irán de la franja ruso-armenia de pórfidos de cobre y molibdeno, con resultados favorables cerca de la ciudad de Tabriz.

Luego, estableció la oficina de exploraciones para la empresa transnacional Texasgulf Inc. en Antofagasta para evaluación de recursos de azufre volcánico en el altiplano de Chile, Bolivia y Perú.

Para el trabajo de exploración primaria se valía solo de una moto todo terreno, con tracción en ambas ruedas, ya que las motos $4 \times 4$ aún no existían. Con su moto estableció el récord mundial de altura, logro que fue publicitado por el fabricante con una foto de Arturo, junto a su moto, en la cima de un volcán. Posteriormente, se abocó a la exploración por metales base para Texasgulf en Chile, Uruguay, Argentina, Bolivia, Perú y, durante un período considerable, también en México.

En 1970, estableció una oficina de exploración para Texasgulf en Windhoek, Namibia, África Sudoccidental, para seleccionar objetivos para exploración. Regresó a Chile en 1971 por razones personales y, desde entonces, se dedicó a su carrera como consultor privado hasta su muerte, actividad que solo interrumpió entre los años 1975 y 1976 en que formó parte del equipo de geólogos de la Empresa Minera Mantos Blancos S.A.

En 38 años como consultor privado, Arturo desarrolló una intensa actividad en todas las empresas e instituciones estatales relacionadas con la minería, como asimismo con las mineras privadas y empresarios mineros grandes y chicos, en las más variadas tareas relacionadas con la exploración, desde el altiplano de Arica hasta Magallanes.

En los últimos 20 años, fue requerido principalmente para actividades de geología aplicada a la ingeniería, generalmente en asociación con empresas consultoras de ingeniería, para evaluación geotécnica de unos 20 proyectos hidroeléctricos en las fases de factibilidad, diseño y construcción tanto en Chile como en Perú (Cheves y Machupicchu), Ecuador (Abitagua) y repetidamente en Nepal (Indrawatti y Middle Marsanyani).

De trato fácil y alegre, compartía en largas tertulias con amigos sus conocimientos acerca de diferentes temas, incluyendo filosofías orientales con las que tuvo contacto, siempre acompañadas de uno o más buenos tintos.

Arturo se caracterizó por su estilo de vida austero, en el que fue educado. De ello, hizo una filosofía de vida de la que nunca se apartó y que no siempre fue bien comprendida por algunas de sus amistades.

Sus dos hijos, Chantal y Martín, de su primera señora, María Llaumett, junto a sus 4 nietos $\mathrm{y}$, especialmente, Dania Troncoso San Martín, su compañera por cerca de 30 años, supieron siempre de su trato generoso y acogedor. A ellos les hacemos llegar nuestras condolencias.

Arturo ya es parte de la historia de la geología en Chile. Cuando él y quien esto escribe fuimos a inscribirnos, en marzo de 1953, en la recién iniciada carrera de geología, en la Universidad de Chile, el Secretario General de la Facultad de Filosofía y Educación, donde residía la carrera, trató de disuadirnos de nuestro propósito con el argumento: 'No hagan tal, jóvenes. Esta carrera no tiene ningún futuro en Chile'.

Erik Klohn H.

Diciembre, 2007 